\title{
Personal and contextual factors related to internalizing problems during adolescence.
}

Alfredo Oliva • Águeda Parra • M. Carmen Reina

\section{Abstract \\ Background}

Over the past decades, ample empirical evidence has been collected about the factors linked to internalizing problems during adolescence. However, there is a lack of research that use holistic approaches to study the joint analysis of a series of contextual and personal variables considered to be related to internalizing problems.

Objective

This cross sectional study analyzes the relationship between internalizing problems during adolescence and a constellation of contextual (parenting and peer relationships) and personal variables, some of which are linked to the control and regulation of emotions.

Method

The sample consisted of 2400 adolescents (1068 boys and 1332 girls) between 12 and 17 years of ages, who were selected in twenty secondary schools located in western Andalusia (Spain). They completed questionnaires in their classrooms. Results

The results showed significant differences depending on the gender of the participant with girls scoring higher than boys in internalizing problems. This gender difference in the prevalence of problems increased with age. Also, significant relationships were discovered among most of the personal and contextual variables analyzed and internalizing problems, both in boys and girls.Our data showed an interesting 
moderating effect, because empathy was positively associated with internalizing problems, but only for girls with low scores on emotional clarity.

Conclusions

The results of this study provide an interesting contribution to the knowledge of contextual and personal factors regarding internalizing problems during adolescence. Among contextual protective factors, the importance of parental affection and attachment to the peer group must be emphasized, while parental psychological control had negative effects. The results also underscore the importance of certain personal variables, such as risk or protection factors, as well as the moderation relationships established between some of them, including the moderating effect of emotional clarity on the relationship between empathy and internalizing problems, although only in the case of girls.

Keywords: risk factors; emotional self-regulation; parenting; internalizing problems; adolescence 


\section{Personal and contextual factors related to internalizing problems during adolescence.}

\section{Internalizing problems in adolescence}

Since Achenbach $(1966 ; 1991)$ divided mental health problems into internalizing and externalizing problems, this classification has been used extensively by researchers, especially by those focusing on behavioral problems during childhood and adolescence. For this author, anxiety, depression and psychosomatic symptoms are the most characteristic expressions of these internalizing problems, which motivate major discomfort and are important causes of morbidity during adolescence. These problems often appear in association with others such as eating disorders, substance abuse or suicide attempts (Ciccheti and Toth, 1998; Graber and Sontang, 2009).

In many cases, biological factors have been pointed out in the increase of these problems after puberty, but there is also empirical evidence about the role played by other personal and contextual factors (Graber and Sontang, 2009). As with other disorders, internalizing problems result from a combination of factors; thus, understanding this phenomenon is only possible through multi-cause models (Haugaard, 2001). That is the approach of this present study, which seeks to study the relationship between a series of personal, family and social factors, together with internalizing problems in a sample of Andalusian adolescents.

Over the past decades, ample empirical evidence has been collected about the variables linked to internalizing problems during adolescence. Starting with gender differences, most of the research coincides in pointing out a greater prevalence of internalizing problems in women (Chen, Mechanic, and Hansell, 1998; Leadbeater, Kuperminc, Blatt, and Hertzog, 1999; Twenge and Nolen-Hoeksema, 2002). Likewise 
in the case of girls, there is clear consensus about an increase of these problems at the onset of puberty. Nevertheless, among boys, the data are not so clear; some studies found no changes, while others found a slight increase throughout adolescence (Angold and Costello, 1995).

\section{Contextual factors related to internalizing problems}

Some studies find a relationship between low socio-economic status (SES) and internalizing problems (Goodman, McEwan, Dolan, Schafer-Kalkhoff, and Adler, 2005; Matud, Guerrero, and Matías, 2006; McLeod and Owens, 2004), while there are also various contextual variables that appear to be associated with the development of internalizing problems during adolescence. Among contextual risk factors linked to internalizing problems, those receiving greater empirical support refer to the family context. Several longitudinal studies have found that an increase in internalizing problems during adolescence was associated with an increase in family conflict, lack of support and affection, and coercive control (Graber and Sontag, 2009). Significant empirical evidence supports the relationship between affection and support in the parenting style, child and adolescent self-esteem and their emotional adjustment (Davidson and Adams, 2013; Dusek and McIntyre, 2003). A parenting style characterized by affection, support and communication toward the child promotes the child's self-esteem and this, in turn, his/her emotional well-being. When talking about parental control, the empirical evidence is somewhat less convincing, as behavioral control based on monitoring and the imposition of limits provides data that indicate a non-significant relationship with internalizing problems. In the case of psychological control, which refers to control that intrudes on the child's emotional development, a positive relationship is very clear (Barber and Harmon, 2002), as it shows more internalizing problems in those children who are psychologically controlled. 
Likewise, relationships with peers, which acquire a special relevance during adolescence, have been considered to be an important influence on emotional adjustment. Thus, internalizing problems have been linked to the quality of friendships (Parker and Asher, 1993), peer attachment (Armsden and Greenberg, 1987; Tambelli, Laghi, Odorisio and Notari, 2012), social isolation (Nangle, Erdley, Newman, Mason, and Carpenter, 2003) and victimization (Yeung Thompson and Leadbeater, 2012). Adolescents with positive peer relationships have better emotional adjustment (Brown and Klute, 2003). In this association, self-esteem plays an important mediating role (Bosacki, Dane, Marini, and YLC-CURE, 2007). A good relationship with peers strengthens self-esteem, which will prevent the emergence of internalizing problems.

\section{Personal factors related to internalizing problems}

Indeed, one of the main personal risk factors is low self-esteem. As of puberty, selfesteem suffers a significant decrease, coinciding with an increase in emotional problems (Robins, Trzesniewski, Tracy, Gosling, and Potter, 2002).

Difficulty in understanding emotions, both their own and those of others, and regulating emotions and moods have been postulated as important risk factors in developing internalizing problems (Bradley, 2000; Lougheed and Hollenstein, 2012). According to Mayer and Salovey (1997) competencies that refer to managing emotions could be considered components of general emotional intelligence that some studies have found to be associated with favorable results in social-emotional adjustment (Gleason, Jensen-Campbell and Ickes, 2009; Hsieh and Stright, 2012; Trentacosta and Fine, 2009). More specifically, it has been found that those who tend to ruminate about negative emotions usually show more depressive symptoms. Continual rumination translates into the preservation of negative emotions rather than coping with them or 
using a distraction strategy (Compas, Connor-Smith, Saltzman, Thomsen and Wadsworth, 2001; Shapero, Hamilton, Liu, Abramson and Alloy, 2013), which does not help these adolescents overcome stressful situations. Boys and girls who tend towards ruminative thinking and have difficulties regulating emotions have more emotional problems (Silk, Steinberg and Morris, 2003). Tolerance to frustration is a variable that is directly related to emotional self-regulation and has proven to be linked to internalizing problems. Young people with high levels of such problems usually have low of frustration tolerance levels (Mahon, Yarcheski, Yarcheski and Hanks, 2007).

Although some studies have analyzed the role of empathy, there is no consensus in this regard. Other studies found a positive relationship between empathy and adolescent psychological adjustment (Gleason, et al. 2009), while others noted that elevated empathy was associated with a greater tendency towards suffering depressive disorders (O'Connor, Berry, Weiss and Gilbert, 2002). These contradictory data indicate that the role of empathy is slightly confusing and worthy of greater research. According to Eisenberg, Murphy and Shepard (1997), empathy is an emotional response that is elicited and congruent with the emotional state of others, and as Hodges and Biswas-Diener (2007) argued, being too empathetic could lead to inconveniences, because paying attention to the suffering of others places the person in a situation of risk if that person lacks strategies to regulate this emotional response. Thus, certain studies carried out on healthcare professionals found that empathy and compassion could lead them to situations of stress and burnout if they are unable to regulate their distress. Empathy may thus be considered as a double-edged sword, promoting caring and compassion but at the same time increasing vulnerability of the physician (Decety, Yang and Cheng, 2010; Figley, 2002; Sabo, 2006). That is why it is only logical to think that certain skills such as knowledge and the regulation of emotions could 
moderate the relationship between empathy and internalizing problem. Subjects with elevated levels of empathy could find themselves in a situation of greater vulnerability but only when they are lacking these emotional skills. This is one aspect that has been studied very little and that we seek to analyze in this study.

\section{Present study and hypotheses}

This work studies emotional adjustment during adolescence using a multi-causal systemic approach, since it analyzes the relationship that personal and contextual factors have on the prevalence of internalizing problems. This study will analyze the contribution that personal (gender, age, empathy, emotional intelligence, tolerance to frustration and self-esteem) and contextual (family socioeconomic status, parental style, and attachment to peers) variables have on internalizing problems during adolescence. Also, we seek to study the role that empathy plays in the development of these problems, analyzing possible effects of interaction between this empathy and other variables related to emotional understanding and regulation.

Our initial hypotheses were that internalizing problems would be more frequent among the girls, particularly older girls, and in adolescents with a lower socioeconomic status. We also expected to find a positive association between these problems and low self-esteem, emotional intelligence and tolerance to frustration. When it came to empathy, we sought to verify the possibility that the relationship between empathy and internalizing problems is moderated by the influence of other emotional variables included in the study, such as emotional clarity and repair. We also expected to find more internalizing problems among those children with worse family relationships (less 
affection, less promotion of autonomy and greater psychological control), and less peer attachment.

\section{Method}

\section{Participants}

The study sample was made up of 2,400 young adolescents (1,068 boys and $1,332$ girls $)$ from 12 to 17 years of age $(M=14.73, S D=1.25)$, who were enrolled in secondary public and private schools located in Western Andalusia. They were selected from 20 schools chosen based on (1) the size of the center (small: less than 600 students or large: over 600 students), (2) socioeconomic status of the area (lower-middle class or upper-middle class), (3) population size (small: less than 30,000 inhabitants or big: over 30,000 inhabitants), and (4) ownership (public or private). At each school, two classrooms were selected randomly for each secondary education course. Only pupils under the age of 18 were selected as part of the sample. $98 \%$ of the participants were Caucasians. With regards to the family composition, $85 \%$ lived in two parent families, $9 \%$ in single parent families, $4 \%$ in stepfamilies, and $2 \%$ in other types of families (adoptive, same sex or foster families).

\section{Measures}

The Revised Family Affluence Scale (Boyce, Torsheim, Currie, and Zamborn, 2006) was used to assess family socioeconomic status. This scale builds an index based on questions referring to the number of cars and computers the family owns, the existence of a room solely for the adolescent, and trips made during holidays. This 
index ranges from 0 to 9 , and can be considered an indicator of the family socioeconomic status.

Scale for the evaluation of the Parenting Style: Oliva, Parra, Sánchez-Queija, and López (2007) designed the scale to evaluate the perception that adolescent children have of various dimensions regarding their parents' educational style. This scale included 41 items scored on a Likert-type scale ranging from 1 (totally disagree) to 6 (totally agree). Although the scale has six sub-scales or dimensions, only four of them were used in this work. Affection and communication: this refers to the parents' expression of support and affection, their availability and the fluency of parent-child communication. Made up of eight items, its reliability coefficient, Cronbach's Alpha was .92. Promotion of autonomy: This evaluates to what degree parents encourage their child to have their own ideas and make their own decisions. It consists of eight items, and reached a Cronbach's Alpha of .88. Behavioral control: This includes six items referring to the establishment of limits and the intents of the parents to be aware of their children's behavior outside the home; Cronbach's Alpha $=.82$. Psychological control: Evaluates the parents' use of manipulating strategies such as emotional blackmail and guilt induction. It is therefore a clearly negative dimension. It has eight items and a Cronbach's Alpha of .86.

Inventory of Parent and Peer Attachment (Armsden and Greenberg, 1987). Peer attachment was assessed with the Spanish-language version (Pardo, Pineda, Carrillo and Castro, 2006) of the sub-scale for peer attachment from this inventory. This sub-scale included 25 items that are scored from 1 to 7 , and evaluate the quality of the relationship with peers. The reliability of the scale according to the Cronbach's Alpha was .73. 
Modified Version in Spanish of the Trait Meta-mood Scale (TMMS-24) is a trait scale for emotional meta-knowledge, adapted and validated in Spain by Fernández-Berrocal, Extremera, and Ramos (2004), based on the Trait Meta-Mood Scale by Salovey, Mayer, Goldman, Turvey, and Palfai (1995). This scale evaluates three dimensions. Emotional attention: This refers to the extent to which people attend to and value their feelings. It has eight items that offered a Cronbach's Alpha of .89. Emotional clarity: This dimension includes eight items that evaluate the clarity of the perception one has of his/her own feelings (Cronbach's Alpha .89). Emotional repair: The use of positive thinking to repair negative moods; it includes eight items (Cronbach's Alpha .85). All items are scored on a scale ranging from 1 (totally disagree) and 7 (totally agree). This scale has proven its reliability for use with adolescents age 12 or older. The reliability coefficient among younger adolescents was the same as for older adolescents.

Basic Empathy Scale: Empathy was assessed with a brief Spanish-language adaptation of the Jolliffe and Farrington (2006) scale. In its original English version, the scale included 20 items that have been reduced by analyzing the items and an exploratory factor analysis. The final version included nine items grouped within two factors that explain the $48.8 \%$ variance. A confirmatory factor analysis using AMOS 20 confirmed this structure, with two second order factors, affective empathy (4 items, Cronbach's Alpha $=.71)$ and cognitive empathy $(5$ items, Cronbach's Alpha $=.73)$, as well as a global first order factor $(\mathrm{RMSA}=.047 ; \mathrm{CFI}=.963 ; \mathrm{GFI}=.983 ; \mathrm{AGFI}=.974)$. The scale obtained a Cronbach's Alpha $=.75$.

Frustration Tolerance Scale: A Spanish-language adaptation of the Stress Tolerance sub-scale that included in the Emotional Quotient Inventory Youth Version was used (Bar-On and Parker, 2000). A factor analysis reduced the 12 initial items-scoring on a scale ranging from 1 (never) to 5 (always)--to eight items grouped within a single 
factor; this explained the $39.4 \%$ variance. A subsequent confirmatory factor analysis provided good adjustment indexes for this one-factor structure $(\mathrm{RMSA}=.047 ; \mathrm{CFI}=$ $.977 ; \mathrm{GFI}=.988 ; \mathrm{AGFI}=.976)$. Cronbach's Alpha was $=.77$.

Self-esteem Scale: Self- esteem was assessed with the Spanish adaptation (Atienza, Moreno, and Balaguer, 2000) of the Rosenberg Self-esteem Scale (1965); it includes ten Likert-type items, with answer options ranging from 1 (totally disagree) to 4 (totally agree). The Cronbach's Alpha for the scale was .82.

Youth Self Report (YSR; Achenbach, 1991): This scale has 112 items with a Likert-type response format comprising three categories and designed to be used with adolescents between 11 and 18 years of age. The Spanish-language version was used (Fonseca, Sierra, Lemos, Paíno and Muñiz, 2012; Lemos, Vallejo, and Sandoval; 2002). All items were to be answered choosing from three options: 0 (not at all true), 1 (somewhat true) and 2 (very true). It includes two sub-scales, with one referring to internalizing or emotional problems and another linked to externalizing or behavioral problems. It also includes a sub-scale of socially desirable behaviors. The scale for internalizing problems (anxiety/depression, withdrawal and somatic complaints)--the only presented in this article--obtained a Cronbach's Alpha of .80.

\section{Procedure}

The objectives of the study were explained to the school principal (head teacher) in person. A passive consent procedure was used to obtain tacit approval from parents. Likewise, active informed consent was sought from students. To guarantee confidentiality, all students completed the questionnaires anonymously. They responded in a one hour group session, in the classroom and before a member of the research team. The study was approved by the University of Seville ethical committee. The authors 
declare they have no conflict of interest with respect to the research, authorship and publication of this paper.

\section{Data analysis}

ANOVA was used to analyze and study the relationship between internalizing problems and the gender and age of the adolescents. The correlations of these problems with other quantitative variables included in the study were also analyzed. To carry out an in-depth analysis of variables related to internalizing problems, hierarchical multiple regressions were used. We decided to analyze the full sample and then boys and girls separately to test whether certain variables had more explanatory power for one gender or another. For the first step, age and family socioeconomic status were included as statistical control. We included variables referred to parenting in the second step, and peer attachment in a third step. Step four included variables linked to perception and emotional control; self-esteem was added to the fifth step. Finally, for the last step, the variables created to analyze the possible effects of interaction between empathy and clarity, and empathy and emotional repair were included following the procedure proposed by Aiken and West (1991). Each variable in the model was centered and interaction terms were created by multiplying the two centered variables. Finally, significant interactions were plotted according to the suggestions of these authors. The regressions for boys and girls were presented separately.

\section{Treatment of missing data}

Some participants failed to complete one or more of the items included in the instruments. If the number of blank items of any scale exceeded $25 \%$, that subject's data for that scale were excluded from the analyses. If it was less than $25 \%$, the missing data were predicted using a single imputation or regression substitution method. This 
procedure involves a regression equation based on the non-missing data to predict expected values for the missing data (Schafer and Graham, 2002). Less than $10 \%$ of participants lacked data with only about $2 \%$ were excluded from the analysis.

\section{Results}

\section{Descriptive and bivariate analyses}

The ANOVA analysis was used to study differences in internalizing problems based on gender and age provided very significant data. Boys scored lower than girls in problems, $F(1,2396)=121.80, p<.001$, eta ${ }^{2}=.048$. Also, significant differences were associated with age, $F(2,2395)=6.72, p=.001$, ta $^{2}=.006$. Using the Tukey's test, the post hoc analyses indicated that the 12 - 13 year-old group differed significantly from the 16 - 17 year-old group ( $p=.001$ ), with older adolescents scoring higher on internalizing problems.

An interaction effect was found between gender and age $(p=.027)$, and although girls presented more problems than boys in all three age groups, these gender differences increased progressively. Among boys, no changes with age were observed in the scores for internalizing problems; however, in girls, the scores increased significantly, $F(2,1328)=9.03, p<.001$, eta $^{2}=.04($ see Table 1$)$

\section{Insert table 1 here}

Pearson correlations between internalizing problems and the variables included in this study are presented separately for boys and girls in Table 2 . In the case of girls, the correlations were significant for most of the variables considered, with the exception of parental behavioral control. More internalizing problems were observed as girls grew older and parental psychological control, empathy and emotional attention increased. 
Correlations were negative for family socioeconomic status, affection and promotion of autonomy in parenting, peer attachment, emotional clarity and repair, frustration tolerance and self-esteem.

\section{$\underline{\text { Insert table } 2 \text { here }}$}

In the case of boys, more internalizing problems were observed when there was an increase of psychological control and attention to their own emotions, and as affection and promotion of autonomy, peer attachment, frustration tolerance and selfesteem decreased. The correlations with the rest of variables were not significant.

\section{Hierarchical regression analysis}

\section{Insert table 3 here}

Table 3 presents the regression analysis results for the factors related to internalizing problems for the total sample and for both boys and girls. In the case of boys, the demographic variables introduced in the first step had no significant contribution, but those referring to parenting, when added in the second step, did explain the 5\% variance in internalizing problems. Parental affection and psychological control were the dimensions that displayed a significant association with internalizing problems. While affection presented a negative relationship, psychological control was positively related. In the third step, and with the inclusion of peer attachment, the explained variance raised to $8.3 \%$, with this variable significantly contributing to a decrease in internalizing problems.

Upon adding the emotional variables in the fourth step, the explained variance increased to $17 \%$. Empathy, emotional attention, and frustration tolerance were responsible for this significant increase. But while the relationship was positive in the 
case of the first two, frustration tolerance showed a negative relationship with internalizing problems. Upon including self-esteem in the fifth step, the explained variance rose to $20.6 \%$ and contributed significantly to reducing the internalizing problems of the boys in the sample. Finally, none of the interaction effects added in the sixth step were significant.

In the regression analysis for girls, the demographic variables included in the first step significantly contributed to explaining the variance in internalizing problems (2.1\%). Both age and socioeconomic status showed a significant relationship with the dependent variable with scores in internalizing problems increasing as age increased and socioeconomic status decreased. The explained variance rose to $13 \%$ with the inclusion of parenting variables. As in the case of boys, the relevant dimensions were affection and psychological control, with one decreasing and the other increasing the problems. Peer attachment added in the third step led to a significant increase, from $13 \%$ to $17.8 \%$, for its negative relationship with internalizing problems. In the fourth step, the variables for empathy, frustration tolerance, attention, clarity and emotional repair raised the explained variance to $32.2 \%$. All of these variables presented a significant relationship with internalizing problems, which was positive in the case of attention and empathy and negative in the other three cases. The inclusion of selfesteem brought the explained variance to $37.6 \%$, due to its negative relationship with internalizing problems. In the sixth and final step, the effects of interaction were added. These were only significant with the interaction of emotional clarity and empathy; this means that emotional clarity moderated the relationship between empathy and internalizing problems. The total percentage of variance explained by all of the predictors was $38 \%$, which is an average effect size.

\section{Insert figure 1 here}


To perform an in-depth analysis of these significant interaction effects detected among girls, three groups in the moderating variable (emotional clarity) were created. Those adolescents with one standard deviation above and below the average fell into the groups of high and low emotional clarity, while those with average scores fell into the group of average emotional clarity. Figure 1 shows the three slopes corresponding to each group based on regression coefficients. The post-hoc analyses (Holmbeck, 2002) indicated that the association between empathy and internalizing problems was significant in the case of the groups with low, $t(1280)=3.43, p<.001$, and average emotional clarity, $t(1280)=2.87, p=.004$, showing that with more empathy, there were also more internalizing problems, but not when the adolescents presented high emotional clarity, $t(1280)=1.12, p>.05$.

\section{Discussion}

The results of this study provide information about the relationship between internalizing problems and certain contextual and personal variables in adolescents. This information could possibly be of interest to design preventive strategies against emotional disorders in adolescence.

Perhaps, the main contribution of our study is the joint analysis of a series of contextual and personal factors considered to be related to internalizing problems. However, in general terms, the effect sizes of many of these relationships were very small. With regards to the contextual factors, both family and peers significantly contributed to explaining internalizing problems, regardless of the gender of the subjects. Thus, of the four parenting variables, two of these were decisive: parental affection, which was demonstrated to be a protective factor, and psychological control, which was revealed as an important risk factor. The relevance of affection suggests the 
importance of parents maintaining a supportive relationship with their children to promote good psychological adjustment (Steinberg, 2001) and to prevent the negative consequences of stressful life events (Costa, Weems and Pina, 2009; Oliva, Jiménez and Parra, 2009). The negative effect of psychological control techniques was also confirmed in our study which coincides with the results of other researchers (Costa and Weems, 2005; Barber and Harmon, 2002; Barber, Olsen, and Shagle, 1994). Intrusive control is usually more frequent among mothers with elevated anxiety (Costa and Weems, 2005; Woodrull-Borden, Morrow, Bourland and Cambron (2002) and it has been suggested as a mediator of the link between maternal and child anxiety. This manipulative control hinders autonomous development in the young person, increasing their feeling of insecurity. Thus, Creveling, Varela, Weems and Corey (2010) found that maternal control was an indirect effect on the child's anxiety through maladaptive cognitive styles characterized by disconnection, rejection and impaired autonomy. It is not surprising that our data indicates psychological control has a negative effect on the emotional well-being of boys and girls, thus increasing their internalizing problems. For the other two dimensions evaluated--behavioral control and the promotion of autonomy-these made no significant contributions. This is probably due to the fact that although they are important components of the parenting style, their positive effects on adolescent development are reflected in other aspects, such as behavioral adjustment or academic performance (Silk, Morris, Kanaya, and Steinberg, 2003). At the same time, the lack of a relationship between the promotion of autonomy and internalizing problems may be a cultural confound. Although individualistic societies have highlighted the role of autonomy during adolescence, in more collectivist cultures, as is the case of Spain, maintaining close affective ties with parents is very probably a requirement for healthy development, and adolescents need not struggle for 
independence. As Kagitcibasi pointed out (1996), promoting autonomy may be more important in individualistic cultures.

It is essential to point out that although the parenting variables contributed significantly to explaining the variance for internalizing problems in girls and boys, the explained variance was much higher among the girls, probably because they showed higher scores for empathy, which coincides with the results of other studies (Mestre, Samper, Frías, and Tur, 2009). This higher empathy places girls in a more vulnerable position when faced with the parental psychological control. Moreover, it is necessary to remember an aspect highlighted by classic studies on gender stereotypes (Bem, 1974; Rosenkrantz, Vogel, Bee, Broverman, and Broverman, 1968), in the sense that the feminine role is linked to expressive features (nurturance or interpersonal sensitivity). These features could make girls feel more pressured to maintain positive family relationships, which would make them more affected by the dynamics of the family relationships established in the home.

While parenting style seems to be an important aspect for psychological adjustment in adolescence, ties with peers were also important, since even when parenting variables were included in the regression, peer attachment provided a significant contribution. These data indicate that having a good relationship with friends could be a key element in protecting adolescents from the emergence of emotional problems. During adolescence, there is a certain degree of distancing with regards to parents. Thus, peers have a strong impact on confidence and emotional support, which increases self-esteem (Bosacki et al., 2007), and protects them when faced with stressful situations. Therefore, adolescents with good relationships with their peers are less prone to developing internalizing problems (Tambelli et al., 2012). 
Likewise, personal variables contributed significantly to explaining the variance in internalizing problems. These problems increased in line with empathy and emotional attention and when frustration tolerance decreased. Among girls, in addition to those variables, the negative relationship between internalizing problems and clarity and emotional repair also had to be added. These data indicate that although we should consider empathy as a positive feature related to prosocial behavior (Carlo and Randall, 2002; Hoffman, 2008), it can also constitute a vulnerability factor for internalizing problems when it is not accompanied by certain skills relative to knowledge and emotional and mood self-regulation. This has been demonstrated in our study through the moderating effect of emotional clarity on the relationship between empathy and internalizing problems, although only in the case of girls. In girls, when the levels of emotional clarity were high, greater empathy was not associated with more internalizing problems, but rather, when clarity was low. This is probably due to the fact that this emotional clarity helps girls reduce the discomfort generated by the empathetic response to the suffering of others (Decety et al., 2010). This result represents a key finding in our study and emphasizes the importance that knowledge of own emotions has when protecting adolescent girls from developing anxiety-depressive problems.

Excessive attention to their own emotions is also a risk factor, probably due to rumination about negative concerns and emotions does not represent an effective coping strategy, but just the opposite (Compass et al., 2001). On the other hand, the ability to understand and regulate their own emotions and tolerate frustration was revealed as important protection factors, as was self-esteem.

This study has taken a holistic or systemic approach to understanding internalizing problems, the prevalence of which usually increases significantly during adolescence, especially among girls. In fact, our results have once again shown the 
existence of major gender-based differences in adolescent emotional adjustment. While at the start of adolescence girls already placed above boys in terms of the prevalence of internalizing problems, throughout this period these differences increased, so that by the age of 17, the greatest gender differences were found. This is an indicator of major differences in the emotional health of boys and girls, which has been documented extensively in the empirical literature (Hyde, Mezulis, and Abramson, 2008; Twenge and Nolen-Hoeksema, 2002).

It is good to point out that the increase in gender differences throughout the second decade of life is not only observed in internalizing problems, but also tendencies have been found in other psychological behaviors or characteristics, such as aggressive behavior, participating in sports or eating disorders (Galambos, Berenbaum, and McHale, 2009; Perry and Pauletti, 2011). As Hill and Lynch (1983) pointed out in their gender intensification hypothesis, the developmental trajectories of boys and girls would be divergent as a consequence of the convergence of a series of biological, social and cognitive factors.

Finally, we would like to refer to some of the limitations of this study, such as its cross-sectional character, which makes it impossible to establish causal relationships. Using adolescents as the only source of information is another limit, which could have increased the correlations between the variables studied. The assessment of emotional intelligence with self-reporting rather than performance tests could also be a limit. However, the test used provided reliable indices even between younger participants. This indicates the possibility of measuring this competence during early adolescence. Nevertheless, we consider that despite those limits, the results of this study contribute to improving our knowledge of the relationship between certain personal and contextual factors and the emotional adjustment of adolescent boys and girls. 


\section{References}

Achenbach, T. M. (1966). The classification of children's psychiatric symptoms: A factor-analytic study. Psychological Monographs, 80, 1-37.

Achenbach, T.M. (1991). Manual for the Child Behavior Checklist / 4-18 and 1991 Profile. Burlington, VT: University of Vermont Department of Psychiatry.

Aiken, L .S., \& West, S. G. (1991). Multiple Regression: Testing and interpreting interactions. Newsbury Park: Sage.

Angold, A., \& Costello E. J. (1995). Developmental epidemiology. Epidemiological Reviews, 17, 74-82.

Armsden, G., \& Greenberg, M. (1987). The inventory of parent and peer attachment: Individual differences and their relationship to psychological well-being in adolescence. Journal of Youth and Adolescence, 16, 427-454. doi:10.1007/BF02202939

Atienza, F. L., Moreno, Y., \& Balaguer, I. (2000). Análisis de la dimensionalidad de la Escala de Autoestima de Rosenberg en una muestra de adolescentes valencianos. [Analysis of the dimensionality of the Scale of Self-esteem of Rosenberg in a sample of Valencian adolescents]. Revista de Psicología Universitas Tarraconensis, 22, 29-42

Barber, B. K., Olsen, J. E., \& Shagle, S. C. (1994). Associations between parental psychological and behavioral control and youth internalized and externalized behaviors. Child Development, 65, 1120 - 1136. doi: 10.1111/j.14678624.1994.tb00807. 
Barber, B. K., \& Harmon, E. L. (2002). Violating the self: parental psycho-logical control of children and adolescents. In B. K. Barber (Ed.), Intrusive parenting: how psychological control affects children and adolescents (pp. 15-52). Washington: American Psychological Association.

Bar-On, R., \& Parker, J. D. A. (2000). The Bar-On Emotional Quotient Inventory: Youth Version (EQ-i:YV): Technical manual. Toronto, Canada: Multi-Health Systems.

Bem, S. L. (1974). The measurement of psychological androgyny. Journal of Consulting and Clinical Psychology, 42, 155-162. doi:10.1037/h0036215 Bosacki, S., Dane, A., Marini, Z., \& YLC-CURA. (2007). Peer relationships and internalizing problems in adolescents: Mediating role of self-esteem. Emotional and Behavioural Difficulties, 12, 261-282. doi: 10.1080/13632750701664293

Boyce, W., Torsheim, T., Currie, C., \& Zamborn, A. (2006). The family affluence scale as measure of national wealth: validation of adolescent self-report measure. Social Indicators Research, 78, 473-487. doi: 10.1007/s11205-005-1607-6

Bradley, S. J. (2000). Affect regulation and the development of psychopathology. Nueva York: Guilford.

Brown, B. B., \& Klute, C. (2003). Friends, cliques, and crowds. In G. R. Adams \& M. D. Berzonsky (Eds.), Blackwell handbook of adolescence (pp. 330-348). Malden, MA: Blackwell.

Carlo, G., \& Randall, B. A. (2002). The Development of a Measure of Prosocial Behaviors for Late Adolescents. Journal of Youth and Adolescence, 31, 31-44. doi: 10.1023/A:1014033032440 
Chen, H., Mechanic, D., \& Hansell, S. (1998). A longitudinal study of self-awareness and depressed mood in adolescence. Journal of Youth and Adolescence, 27, 719734.

Compas, B. E., Connor-Smith, J. K. Saltzman, H., Thomsen, A.H., \& Wadsworth, M. E. (2001). Coping with stress during childhood and adolescence: Problems, progress, and potential in theory and research. Psychological Bulletin, 127, 87127. doi: 10.1037/0033-2909.127.1.87

Costa, N. M \& Weems, C. F. (2005). Maternal and child anxiety: Do attachment beliefs or children's perceptions of maternal control mediate their association? Social Development, 14, 574-590.

Costa, N. M., Weems, C. F., \& Pina, A. A. (2009). Hurricane Katrina and youth anxiety: The role of perceived attachment beliefs and parenting behaviors. Journal of Anxiety Disorders, 23, 935-941. doi: 10.1016/j.janxdis.2009.06.002

Creveling, C. C., Varela, R. E., Weems, C. F., \& Corey, D. M. (2010). Maternal control, cognitive style, and childhood anxiety: A test of a theoretical model in a multiethnic sample. Journal of Family Psychology, 24, 439-448. doi:

$10.1037 / \mathrm{a} 0020388$

Davidson, S., \& Adams, J. (2013). Adversity and internalizing problems among rural Chinese adolescents: The roles of parents and teachers. International Journal of behavioral Development, 35, 530-541. doi: 10.1177/F0165025413503421.

Decety, J., Yang, C.Y., \& Cheng, Y. (2010). Physicians down-regulate their pain empathy response: an event-related brain potential study. Neuroimage, 50, 16761682. doi: 10.1016/j.neuroimage.2010.01.025 
Dusek, J. B., \& McIntyre J. G. (2003). Self-concept and self-esteem development. In G. R. Adams, \& Berzonsky, M. D. (Eds.), Blackwell Handbook of Adolescence (pp. 290-309). Malden MA: Blackwell Publishing.

Eisenberg, N., Murphy, B., \& Shepard, S. (1997). The development of empathic accuracy. In W. J. Ickes, (Ed), Empathic accuracy. (pp. 73-116). New York: Guilford Press.

Fernández-Berrocal, P., Extremera, N., \& Ramos, N. (2004). Validity and reliability of the Spanish modified version of the trait meta-mood scale. Psychological Reports, 94, 751-755.

Figley, C.R. (2002). Compassion fatigue: psychotherapists' chronic lack of selfcare. Journal of Clinical Psychology. 58, 1433-1441.

Fonseca, E., Sierra, S., Lemos, S., Paino, M., \& Muñiz, J. (2012). Dimensional structure and measurement invariance of the youth self-report across gender and age. Journal of Adolescent Health, 50, 148-153.

Galambos, N. L., Berenbaum, S. A., \& McHale, S. M. (2009). Gender development in adolescents. In R. M. Lerner \& L. Steinberg (Eds.), Handbook of adolescent psychology: Vol. 1. Individual bases of adolescent development (pp. 305-337). Hoboken, NJ: Wiley.

Gleason, L.A., Jensen-Campbell, L. A., \& Ickes, W. (2009). The role of empathic accuracy in adolescents' peer relations and adjustment, Personality and Social Psychology Bulletin 35, 997-1011. doi: 10.1177/0146167209336605

Goodman, E., McEwan, B. S., Dolan, L. M., Schafer-Kalkhoff, T., \& Adler, N. E. (2005). Social disadvantage and adolescent stress. Journal of Adolescent Health, 37, 484-492. doi:10.1016/ j.jadohealth.2004.11.126

Graber, J. A., \& Sontag, L. M. (2009). Internalizing problems during adolescence. En R. 
M. Lerner \& L. Steinberg (Eds.), Handbook of adolescent psychology, (pp. 642682). New York: John Wiley \& Sons, Inc.

Haugaard, J. J. (2001). Problematic behaviors during adolescence. New York: McGraw-Hill.

Hill, J. P., \& Lynch, M. E. (1983). The intensification of gender-related role expectations during early adolescence. In J. Brooks-Gunn \& A. C. Petersen (Eds.), Girls at puberty: Biological and psychosocial perspectives (pp. 201-228) New York: Plenum Press.

Hodges, S., \& Biswas-Diener, R. (2007). Balancing the empathy expense account: Strategies for regulating empathic response. In Farrow, T.F.D., \& Woodruff, P.W.R. (Eds.), Empathy in Metal Illness and Health (pp. 389-407). Cambridge, UK : Cambridge University Press

Hoffman, M. L. (2008). Empathy and prosocial behaviour. In Lewis, M., Havilandjones, J. M. \& L. Feldman (Eds.), Handbook of emotions (pp. 440-455). Guilford Press: New York.

Holmbeck, G. N. (2002). Post-hoc probing of significant moderational and mediational effects in studies of pediatric populations. Journal of Pediatric Psychology, 27, 87. doi: 10.1093/jpepsy/27.1.87

Hsieh, M., Stright, A.D. (2012). Adolescents emotion regulation strategies, selfconcept, and internalizing problems. Journal of Early Adolescence, 32, 876-9096. doi: 10.1093/jpepsy/27.1.87

Hyde, J. S., Mezulis, A. H., \& Abramson, L. Y. (2008). The ABCs of depression: Integrating affective, biological and cognitive models to explain the emergence of the gender difference in depression. Psychological Review, 115, 291-313. 
doi: 10.1037/0033-295X.115.2.291

Jolliffe, D., \& Farrington, D. P. (2006). Development and validation of the Basic Empathy Scale. Journal of Adolescence, 29, 589-611. doi: 10.1016/j.adolescence. 2005.08

Kagitcibasi, C. (1996). The autonomous-relational self: A new synthesis. European Psychologist, 1, 180-186..010

Laursen, B., Coy, K. C., \& Collins, W. A. (1998). Reconsidering changes in parentchild conflict across adolescence: A meta-analysis. Child Development, 69, 817832. doi: $10.2307 / 1132206$

Leadbeater, B. J., Kuperminc, G. P. Blatt, S. J., \& Hertzog, C. (1999). A multivariate model of gender differences in adolescents' internalizing and externalizing problems. Developmental Psychology, 35, 1268-1282. doi: 10.1037/00121649.35.5.1268.

Lougheed, J. P., \& Hollenstein, T. (2012). A limited repertoire of emotion regulation strategies is associated with internalizing problems in adolescence. Social Development, 21, 704-721. doi:10.1111/j.1467-9507.2012.00663.x

Lemos, S., Vallejo, G., \& Sandoval, M. (2002). Estructura factorial del Youth Self Report [Factorial structure of the Youth Self-Report]. Psicothema, 14, 816-822.

Mahon, N.E., Yarchesi, A., Yarchesi, T.J., \& Hanks, M.M. (2007). Relations of low frustration tolerance beliefs with stress, depression, and anxiety in young adolescents. Psychological Reports, 100, 98-100.

Mayer, J.D., \& Salovey, P. (1997) What is emotional intelligence? In P. Salovey \& D. Sluyter (Eds). Emotional development and emotional intelligence: Implications for educators (pp. 3-31) New York: Basis Books. 
Matud, M. P., Guerrero, K., \& Matías, R. (2006). Relevancia de las variables sociodemográficas en las diferencias de género. International Journal of Clinical and Health Psychology, 6, 7-21.

McLeod, J. D., \& Owens, T. J. (2004). Psychological well-being in the early life course: variations by socioeconomic status, gender, and race/ethnicity. Social Psychology Quarterly, 67, 257-278. doi: 10.1177/019027250406700303

Mestre, M. V., Samper, P., Frías, M. D., \& Tur, A. M. (2009). Are Women more empathetic than men? A longitudinal study in adolescence. The Spanish Journal of Psychology, 12, 76-83. doi: 10.1017/S1138741600001499

Nangle, D. W., Erdley, C. A., Newman, J. E., Mason, C. A., \& Carpenter, E. M. (2003). Popularity, friendship quantity, and friendship quality: Interactive influences on children's loneliness and depression. Journal of Clinical Child and Adolescent Psychology, 32, 546-555. doi: 10.1207/S15374424JCCP3204_7

O’Connor, L. E., Berry, J. W., Weiss, J., \& Gilbert P., (2002). Guilt, fear, submission, and empathy in depression. Journal of affective disorders, 71, 19-27. doi:10.1016/S0165-0327(01)00408-6

Oliva, A., Parra, A., Sánchez-Queija, I., \& López. F. (2007). Estilos educativos materno y paterno: evaluación y relación con el ajuste adolescente [Maternal and parental parenting style; Assessment and relationship with adolescent adjustment]. Anales de Psicología, 23, 49-56.

Oliva, A. Jiménez, J.M., \& Parra, A. (2009). Protective effects of supportive family relationships and the influence of stressful life events on adolescent adjustment. Anxiety, Stress \& Coping, 22, 137-152. doi: $10.1080 / 10615800802082296$ 
Pardo, M. E., Pineda, S., Carrillo, S., \& Castro, S. (2006). Análisis psicométrico del inventario de apego con padres y pares en una muestra de adolescentes colombianos [Psychometric Analysis of the Inventory of Parent and Peer Attachment in a Sample of Colombian Adolescents]. Interamerican Journal of Psychology, 40, 289-302.

Parker, J. G., \& Asher, S. R. (1993). Friendship and friendship quality in middle childhood: links with peer group acceptance and feelings of loneliness and social dissatisfaction. Developmental Psychology, 29, 611-621. doi:10.1037/00121649.29.4.611

Perry, D. G., \& Pauletti, R. E. (2011). Gender and adolescent development. Journal of Research on Adolescence, 21, 61-74. doi: 10.1111/j.1532-7795.2010.00715.x

Robins, R.W., Trzesniewski, K.H., Tracy, J.L., Gosling, S.D., \& Potter, J. (2002). Global self-esteem across the lifespan. Psychology and Aging, 17, 423-434. doi: 10.1037/0882-7974.17.3.423

Rosenkrantz, P., Vogel, S.R., Bee, H., Broverman, I.K., \& Broverman, D.M. (1968). Sex-role stereotypes and self-concepts in college students. Journal of Consulting and Clinical Psychology, 32, 287-95.

Rosenberg, M. (1965). Society and the adolescent self-image. Princeton, NJ: Princeton University Press.

Sabo, B. M. (2006). Compassion fatigue and nursing work: can we accurately capture the consequences of caring work. Interational Journal of Nursing Practice, 12, 136-142. doi: 10.1111/j.1440-172X.2006.00562.x

Salovey, P., Mayer, J. D., Goldman, S. L., Turvey, C., \& Palfai, T. P. (1995). Emotional attention, clarity, and repair: Exploring emotional intelligence using the Trait 
Meta-Mood Scale. In J. W. Pennebaker (Ed.), Emotion, Disclosure, \& Health (pp. 125-151). Washington: American Psychological Association.

Schafer, J. L., \& Graham, J. W. (2002). Missing data: Our view of the state of the art. Psychological Methods, 7, 147-177. doi: 10.1037/F1082-989X.7.2.147

Shapero, B. G., Hamilton, J. L., Liu, R. T., Abramson, L. Y., \& Alloy, L. B. (2013). Internalizing symptoms and rumination: The prospective prediction of familial and peer emotional victimization experiences during adolescence. Journal of Adolescence, 36, 1067-1076. doi: 10.1016/j.adolescence.2013.08.011

Silk J.S. Steinberg, L., \& Morris A.S. (2003). Adolescents' emotion regulation in daily life: Links to depressive symptoms and problem behavior. Child Development, 74, 1869-1880. doi: 10.1046/j.1467-8624.2003.00643.

Silk, J., Morris, A., Kanaya, T., \& Steinberg, L. (2003). Psychological control and autonomy granting: Opposite ends of a continuum or distinct constructs? Journal of Research on Adolescence, 13, 113-128. doi: 10.1111/15327795.1301004

Steinberg, L. (2001). We know some things: Parent-adolescent relationships in retrospect and prospect. Journal of Research on Adolescence, 11, 1-19. doi: $10.1111 / 1532-7795.00001$

Trentacosta, C. J., \& Fine, S. E. (2010). Emotion knowledge, social competence, and behavior problems in childhood and adolescence: A meta-analytic review. Social Development, 19, 1-29. Doi:10.1111/j.1467-9507.2009.00543.x

Yeung Thompson, R. S., \& Leadbeater, B. J. (2013). Peer victimization and internalizing symptoms from adolescence into young adulthood: building strength through emotional support. Journal of Research on Adolescence, 23, 290-303.doi/10.1111/j.1532-7795.2012.00827.x. 
Tambelli, R., Laghi, F., Odorisio, F., \& Notari, V. (2012). Attachment relationships and in-ternalizing and externalizing problems among Italian adolescents. Journal of Youth and Service Review, 34, 1465-1471.

Twenge, J. M., \& Nolen-Hoeksema, S. (2002). Age, gender, race, socioeconomic status, and birth cohort differences on the Children's Depression Inventory: A metaanalysis. Journal of Abnormal Psychology, 111, 578-588. doi: 10.1037/0021843X.111.4.578

Woodruff-Borden, J. W., Morrow, C., Bourland, S. L., \& Cambron, S. L (2002).. The behavior of anxious parents: Examining mechanisms of transmission of anxiety from parent to child. Journal of Clinical Child and Adolescent Psychology, 31, 364-374.

Acknowledgments: This study was funding by the Ministry of Health of the Junta de Andalucia (Spain). 


\section{Figures and tables}

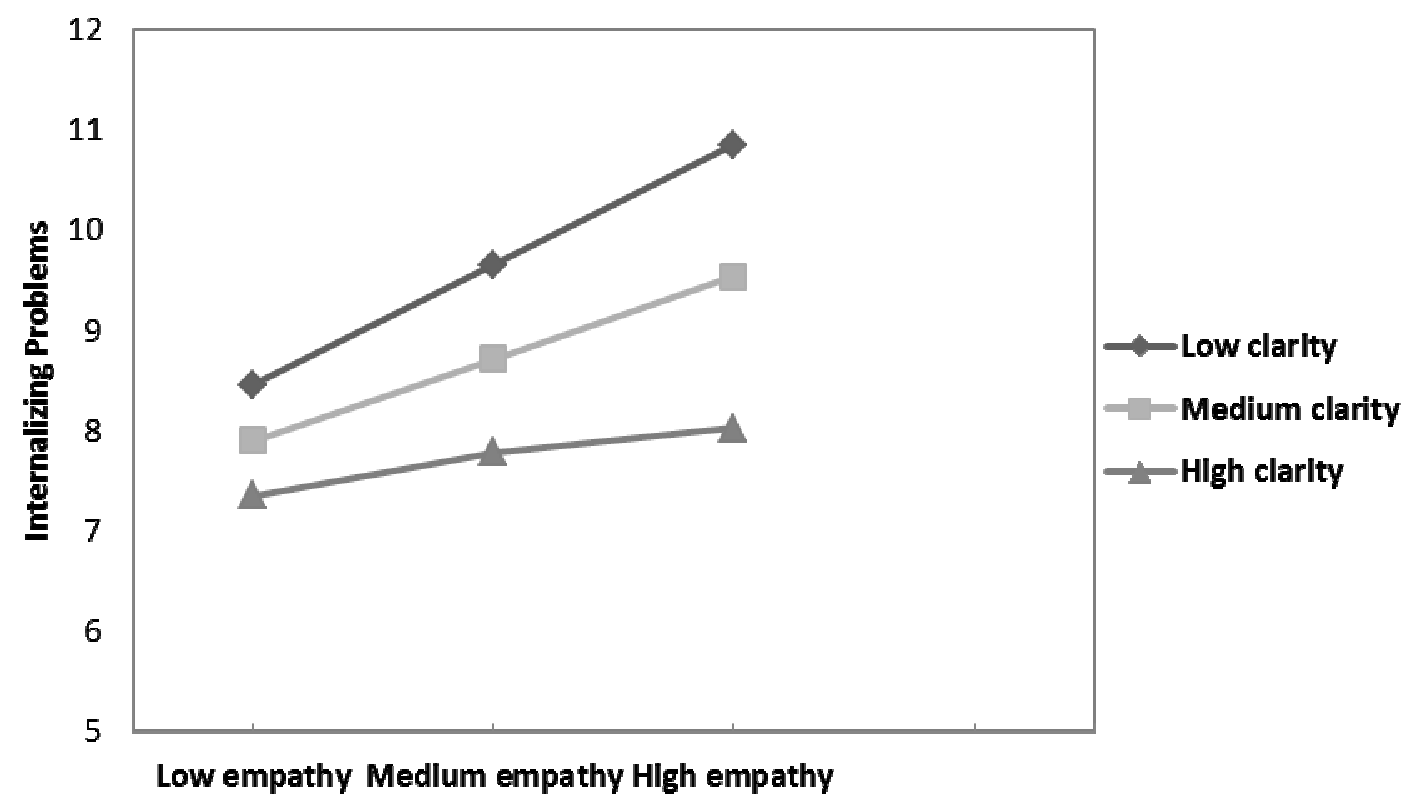

Figure 1.Moderator effects of emotional clarity on the empathy-internalizing problems relationships (only girls)

Table 1

Internalizing problems by gender and age

\begin{tabular}{|c|c|c|c|c|c|c|}
\hline \multirow[b]{2}{*}{ Years } & \multicolumn{2}{|c|}{ Boys } & \multicolumn{2}{|c|}{ Girls } & \multicolumn{2}{|c|}{ Total } \\
\hline & $M$ & $S D$ & $M$ & $S D$ & $M$ & $S D$ \\
\hline $12-13$ & 6.57 & 4.90 & 7.72 & 5.51 & 7.19 & 5.26 \\
\hline $14-15$ & 6.27 & 4.98 & 8.96 & 5.57 & 7.79 & 5.48 \\
\hline $16-17$ & 6.82 & 4.81 & 9.60 & 5.63 & 8.35 & 5.45 \\
\hline Total & 6.50 & 4.91 & 8.91 & 5.61 & 7.84 & 5.45 \\
\hline
\end{tabular}


Table 2

Correlations between internalizing problems and the variables of the study (boys and girls). Means and Standard deviations also included.

\begin{tabular}{llllll}
\hline Internalizing problems & & & & \\
\hline & Boys & Girls & Total & $M$ & $S D$ \\
\hline Sociodemographic variables & & & & & \\
\hline Age & .02 & $.11^{* * *}$ & $.07^{* * *}$ & 14.73 & 1.25 \\
Socio-economic status & -.05 & $-.12^{* * *}$ & $-.10^{* * * *}$ & 5.75 & 1.97 \\
\hline Contextual variables & & & & & \\
\hline Affection/Communication & $-.16^{* * *}$ & $-.27^{* * *}$ & $-.21^{* * *}$ & 5.03 & .86 \\
Promotion of autonomy & $-.14^{* * *}$ & $-.19^{* * *}$ & $-.14^{* * *}$ & 4.62 & .94 \\
Behavioral control & .02 & .01 & .03 & 4.61 & 1.04 \\
Psychological control & $.16^{* * *}$ & $.29^{* * *}$ & $.22^{* * *}$ & 3.00 & 1.11 \\
Peer attachment & $-.25^{* * *}$ & $-.29^{* * *}$ & $-.21^{* * * *}$ & 4.92 & .57 \\
\hline Personal variables & & & & & \\
\hline Emotional attention & $.11^{* * *}$ & $.21^{* * *}$ & $.19^{* * *}$ & 3.43 & .88 \\
Emotional clarity & -.03 & $-.11^{* * *}$ & $-.09^{* * *}$ & 3.44 & .85 \\
Emotional repair & -.03 & $-.17^{* * *}$ & $-.14^{* * * *}$ & 3.47 & .84 \\
Frustration tolerance & $-.30^{* * *}$ & $-.36^{* * *}$ & $-.33^{* * * *}$ & 5.22 & 1.09 \\
Empathy & .03 & $.09^{* *}$ & $.14^{* * * *}$ & 3.76 & .59 \\
Self-esteem & $-.33^{* * *}$ & $-.42^{* * *}$ & $-.41^{* * * *}$ & 3.16 & .48 \\
\hline & & & &
\end{tabular}

$* p<.05, * * p<.01, * * p<.001$ 
Table 3

Hierarchical multiple regressions predicting internalizing problems in boys and girls

\begin{tabular}{|c|c|c|c|c|c|}
\hline & \multirow[b]{2}{*}{ Predictors } & \multicolumn{2}{|c|}{ Boys } & \multicolumn{2}{|r|}{ Girls } \\
\hline & & Beta & $\begin{array}{l}R^{2} \text { and } \\
\text { significance } \\
\text { of } R^{2} \text { change }\end{array}$ & Beta & $\begin{array}{l}R^{2} \text { and } \\
\text { significance of } \\
R^{2} \text { change }\end{array}$ \\
\hline \multirow[t]{2}{*}{ Step 1} & Age & .03 & .004 & $.10 * *$ & $.020 * * *$ \\
\hline & Socioeconomic status & -.06 & & $-.10 * *$ & \\
\hline \multirow[t]{4}{*}{ Step 2} & Affection/comunic. & $-.10 *$ & $.048 * * *$ & $-.19 * * *$ & $.126 * * *$ \\
\hline & Promotion autonom. & -.07 & & .04 & \\
\hline & Behavioral control & .04 & & .00 & \\
\hline & Psychological control & $.12 * *$ & & $.23 * * *$ & \\
\hline Step 3 & Peer attachment & $-.20 * * *$ & $.083 * * *$ & $-.23 * * *$ & $.174 * * *$ \\
\hline \multirow[t]{5}{*}{ Step 4} & Emotional attention & $.12 * *$ & $.170 * * *$ & $.22 * * *$ & $.315^{* * *}$ \\
\hline & Emotional clarity & -.07 & & $-.11 * * *$ & \\
\hline & Emotional repair & .00 & & $-.09 * *$ & \\
\hline & Frustration tolerance & $-.25 * * *$ & & $-.24 * * *$ & \\
\hline & Empathy & $.11 * *$ & & $.12 * * *$ & \\
\hline Step 5 & Self-esteem & $-.21 * * *$ & $.206^{* * * *}$ & $-.27 * * *$ & $.369 * * *$ \\
\hline \multirow[t]{2}{*}{ Step 6} & Clarity x empathy & .04 & .208 & $-.08 * *$ & $.380 * * *$ \\
\hline & Repair x empathy & .01 & & .01 & \\
\hline
\end{tabular}

$* p<.05, * * p<.01, * * * p<.001$ 